\title{
ANATOMO-FUNCTIONAL CLASSIFICATION OF THE HAND POST-TRAUMATIC SOFT TISSUE DEFECTS
}

DOI: 10.36740/WLek202108121

\author{
Ihor R. Trutyak, Nazar R. Kalynovych, Roman I. Trutiak, Maria Y. Kuzeikiv \\ DANYLO HALYTSKY LVIV NATIONAL MEDICAL UNIVERSITY, LVIV, UKRAINE
}

\begin{abstract}
The aim: Develop a classification of post-traumatic soft tissue defects of the hand to standardize the care of this group of patients. And in order to simplify the choice of plastic technic for post-traumatic soft tissue defects of the hand by surgeons and traumatologists.

Materials and methods: We analyzed the treatment of 54 patients with hand injury and PTSTD. 14 physicians used AFC in the choice of surgical method for the closure of PTSTDH. The practical application of AFC and effectiveness of providing medical care to patients with PTSTDH was performed on a ten-point scale by anonymous questioning immediately at the time of discharge from the hospital and 6 months after the injury.

Results: The results of the practical application analysis of AFC by physicians were as follows: «convenience» $-8.7 \pm 0.6$; «usefulness» is $9.4 \pm 0.2$. The results of treatment for 54 patients were: hands «functionality» $-8,3 \pm 0,4$, «aesthetics» $-7,6 \pm 1,7$. The results in the retrospective group, in which the AFC was not applied, were as follows: «functionality» $-6.8 \pm 0.7$, and «aesthetics» $-5.6 \pm 1.1$

Conclusions: The proposed AFC of PTSTDH help to choose the proper method of surgical management and get good results.
\end{abstract}

KEY WORDS: soft-tissues defect, hand trauma, hand injury

Wiad Lek. 2021;74(8):1900-1904

\section{INTRODUCTION}

The hand is characterized by a complex anatomical structure and at the same time polyfunctionality. That's way, providing medical care to patients with hand injury requires the use and selection of the most optimal ways and methods to achieve a good aesthetic and functional result. [1,2]

Special attention is to hand injury, which is associated with post-traumatic soft-tissue defect (PTSTDH). But, there is no objective classification to assess the severity of hand injury with soft-tissue defect (STD) and help in choosing the best treatment method. It leads to poor treatment outcomes and an increase in disability in this group of patients. [3]

The analysis of the available classifications in Ukrainian and world literature showed that some are too cumbersome, and others don't contain the necessary characteristics of PTSTDH to choose the optimal surgical tactic. [4]

In addition, we haven't found in analyzed literature a definitive classification of the hand injury with STD based on their metric data and anatomical features, and it is reported by other researchers. [5]

Systematization of PTSTDH should be based on characteristics, which would include all components and the same time allow practitioners to choose the most appropriate treatment. It is necessary for the practical application, in our opinion.

\section{THE AIM}

Develop a classification of post-traumatic soft tissue defects of the hand to standardize the care of this group of patients. And in order to simplify the choice of plastic technic for post-traumatic soft tissue defects of the hand by surgeons and traumatologists.

\section{MATERIALS AND METHODS}

We have analyzed prospectively of all surgical cases with hand injury and PTSTD. Fifty four patients were treated in the Surgery Department at the 8th Lviv City Hospital. The anatomic-functional classification (AFC) was used to classify of PTSTDH in all cases. The number of physicians, who used AFC in the choice of surgical method for the closure of PTST$\mathrm{DH}$, was 14. The practical application of AFC was evaluated on a ten-point scale by anonymous questionnaire of physicians after patient's discharge from the hospital. It included such criteria: "convenience" and "utility». The evaluation of the effectiveness of providing medical care to patients with PTSTDH also was performed on a ten-point scale by anonymous questioning immediately at the time of discharge from the hospital and 6 months after the injury. Evaluation criteria were: "functional result" and "aesthetic result".

\section{RESULTS AND DISCUSSION}

The practical application of AFC according to anonymous questionnaire of physicians after patient's discharge from the hospital rated on a ten-point scale as follows: "convenience" $-8,7 \pm 0,6$; "utility" is $9,4 \pm 0.2$.

The treatment results of 54 patients were assessed on a ten-point scale by anonymous questioning of patients 
immediately at the time of discharge and 6 months after the injury. The index of "functionality" of the hand after the trauma was $-8,3 \pm 0,4$, and "aesthetics" - 7,6 $\pm 1,7$, and 6 months after the injury $-8,7 \pm 0,3$, and $7,4 \pm 1,4$. By comparison, the results obtained in a similar way in the retrospective group, in which the AFC was not applied, were as follows: "functionality" - $6.8 \pm 0.7$, and "aesthetics" $-5.6 \pm 1.1, \mathrm{z}$ and 6 months after the injury $-5,7 \pm 0,8$, and $5,4 \pm 0,7$.

Based on the analysis of existing classification systems for traumatic injuries of the hand and clinical observations, we have identified the main criteria . It is important in choosing the proper method of surgical management. These criteria formed the basis of the headings that we used to arrange the PTSTDH.

One of the important criteria on which both surgical tactics and the result of treatment depend is the localization of STD on the anatomic sites of hand. Therefore, PTSTDH can be on the palmar and dorsal surface and circular by it anatomical localization and distribution. In addition, the palmar surface of the hand is divided into the area of the thenar, the middle palmar space and the hypothenar, as these areas differ in anatomical structure, physiological position and functional load.

The covers of the dorsal surface have the same anatomical structure and carry a similar functional load. A separate approach in treatment and diagnostic procedures regards the fingers of the hand, due to their functional activity. We have introduced abbreviations of names for this classification, in order to simplify the formulation of the diagnosis and to form the database archive. So, localization was designated by the letter of the Latin alphabet "L" (location), and the anatomical parts of the hand respectively: «t» (thenar), «mp» (middle palmar), «h» (hypothenar), «f» (finger), «d» (dorsal) and totally STD of hand segments - «C» (circular).

When choosing the method of plastic closure of PTST$\mathrm{DH}$, it is important to consider its area [6]. Determining the area exactly in relative (percent) values allows you to evaluate the possibility of using for the plastics of local tissues or regional flaps, as opposed to determining the area of the wound in absolute values $[7,8]$.

That's why we divided the wound defects depending on the ratio of the area of STD (S1) to the area of the corresponding anatomical area of the hand (thenar, the middle palmar space, hypothenar, finger, dorsal surface of the hand) (S2), into the following groups: minimal, medium and maximal.

$$
\begin{aligned}
& \text { "Min." = S1x100\% / S2 = } \leq 25 \% \text {; } \\
& \text { "Med." = S1x100\% / S2 = 25-75\% } \\
& \text { "Max." = S1x100\% / S2 = } \geq 75 \%
\end{aligned}
$$

The area of the defect classified under the above headings is marked next to the defect localization article. We didn't add an additional area mark in order not to increase the classification.

The depth of the defect is also important to determine treatment management, in particular when choosing the method of plastic closure of STD, namely which of the anatomically important structures are lost and which struc- tures form the bottom of the wound defect. It is known the use of the full-thickness skin grafts requires good vascularization of the recipient bed tissues. So muscles refer to well vascularized tissues, but tendons and bones to structures with impaired blood supply

To optimize the choice of treatment management, we divide STD into surface and deep. Superficial STDs included wounds within the skin and subcutaneous fat. The bottom of such wounds is subcutaneous fat or superficial fascia. Deep STDs include wounds with the absence of skin, subcutaneous fat, superficial fascia, the bottom of which have tendons or bones, or damage to the latter. This group included traumatic amputation of the segments as exposed damaged bone structures. Isolation of defects of vascular and nervous structures in the context of choosing plastic is not considered necessary, since there is a clearly defined tactic of rendering surgical procedure in such clinical cases. In case of damage to the vessels that feed the segment of the hand - a restoration of their integrity or autovenous plastic. Similarly, it applies to nerve injury. This section was designated by the letter " $D$ " (deep) with division into subgroups: "s" (superficial) and "p" (profound) for making a clinical decision and archiving.

Important for the timing and method of plastic closure of STD is the wound characteristic in relation to infection. Aseptic wounds are postoperative wounds with full compliance with aseptic rules. Contaminated wound are all other non-surgical wounds that contain microorganisms, but there are no clinical signs of the inflammatory process. Infected wounds are wounds that already have an infectious process with an appropriate clinical sing. For making a clinical decision this section was designated by the letter "I" (infection) with the division into subgroups: "ni" (no infection), "li" (low infection) and "i" (infected).

Although the closure of STD is an important task in providing medical care to patients with the hand trauma to return the patient to the normal lifestyle, the diagnosis and repair of other damaged structures of the hand are equally important. Therefore, we identified monostructural, multiple, and polystructural trauma. Monostructural trauma is the damage to one structure of one segment of the hand. It is a wound defect in the skin and subcutaneous fatty tissue of the hand in this group of patients. Multiple trauma is traumatic damage to several homogeneous structures of the hand, such as several tendons or several STDs. Polystructural trauma is damage to various structures of the hand, such as STD and damage to tendons and bones. Separate group included traumatic amputation of fingers and hands (incomplete, subtotal and complete). Incomplete traumatic amputation is considered to be such damage in which the injured segment is retained on the soft tissues, which provide venous outflow of blood, but do not provide its arterial nutrition. Subtotal traumatic amputation is injury in which the segment is held on a structure that does not provide any blood flow to the detached segment, such as tendons. If the detached segment is located separately from the limb it's called total traumatic amputation. When making a clinical decision, this heading was designated by the letter "VT" 


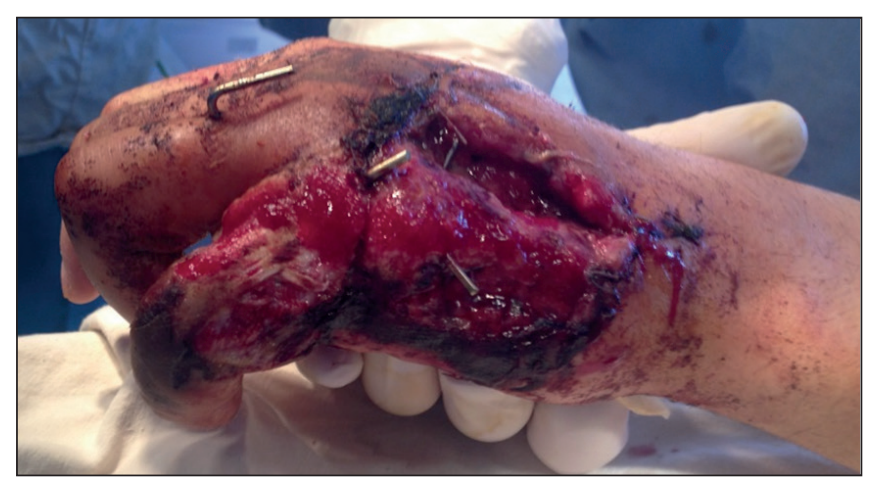

Fig. 1. Lacerated-scalped wound of the left hand with soft tissue defect L(F5med,s+Dmed,s+min,d),lli,VTpt,P+. 3 days after injury.

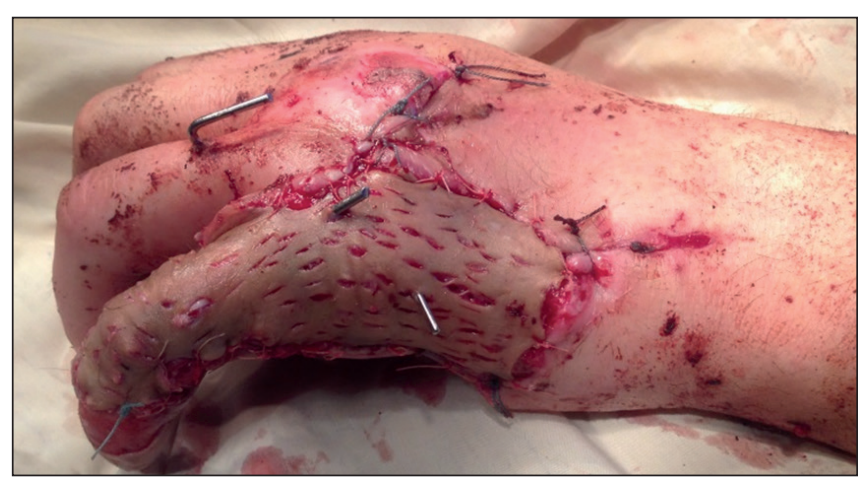

Fig. 2. Lacerated-scalped wound of the left hand with soft tissue defect L(F5med,s+Dmed,s+min,d),lli,VTpt,P+. 5 days after injury. Delayed debridement of the wound and free thin skin graft plastic.
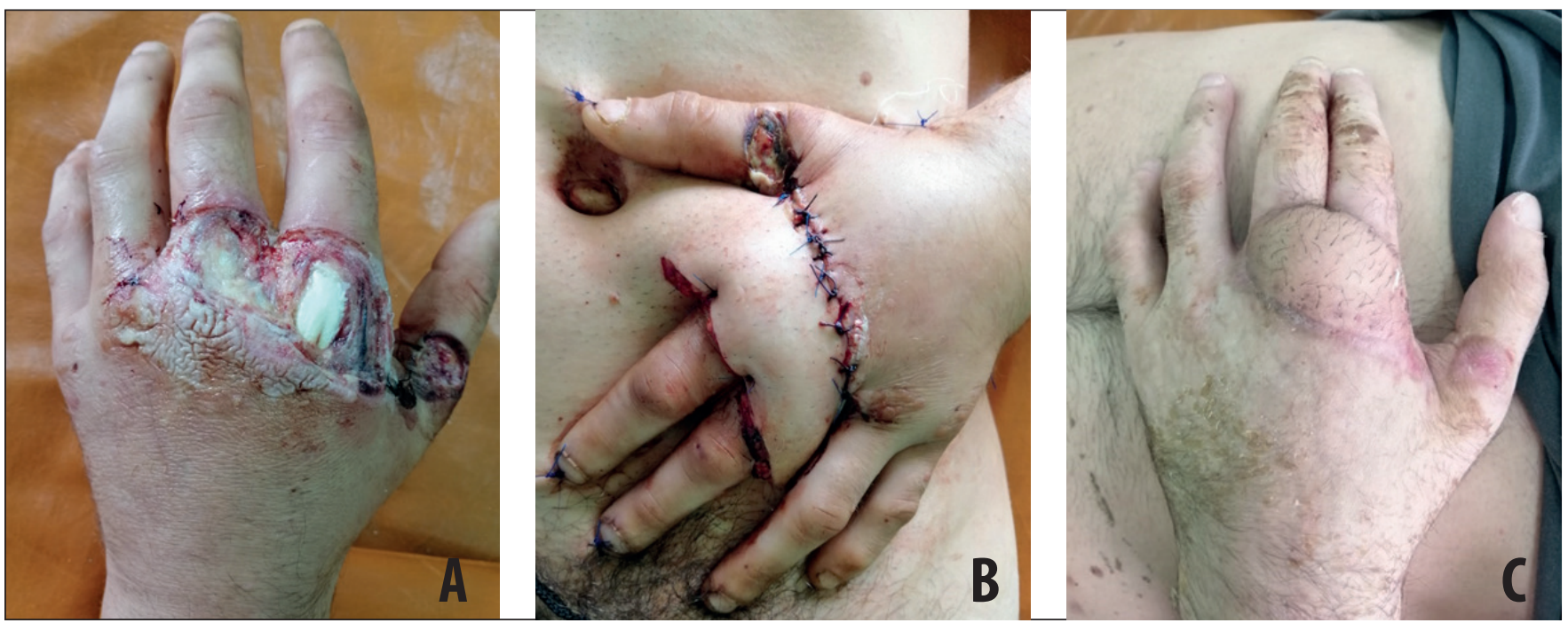

Fig. 3. A. Patient P.. Diagnosis: Thermo-mechanical wound of the left hand with a soft tissue defect. L(F1min, $s+F 2 m i n, d+F 3 m i n, s+d, m i n, p)$, lli, VTmt, $P-$. B. Using McGregor flap to plastic soft tissue defect. C. After treatment.
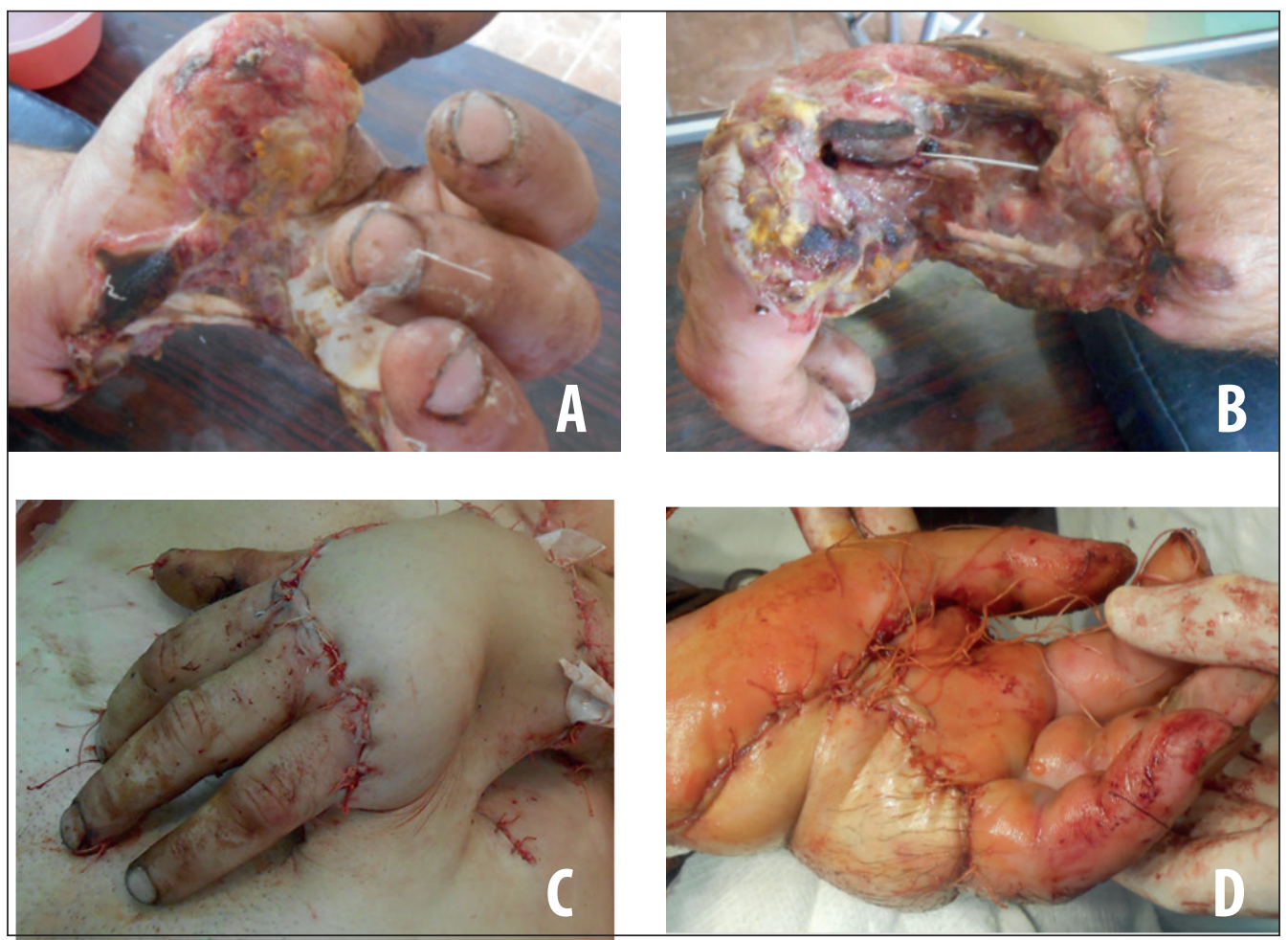

Fig. 4. A, B. Patient R. Diagnosis: Posttraumatic wound of the left hand with a soft tissue defect. L(Tmed,s+MPmed,s+Hmax,d+Dmed, s+d), Ili,VTpt,P-. C, D. Using McGregor flap to plastic soft tissue defect. 
(volume trauma) with division into subgroups: "m" (mono trauma), "mt" (multiple trauma), "pt" (polystructural trau$\mathrm{ma})$, and "a" (amputation).

Determination of dominant injury, shock correction, and stabilization of general condition are vital for patients with combined hand injury and other anatomic and functional areas (head, chest, abdomen, pelvis). So, providing medical care for STD to this patient group has certain features. For the purpose of differential treatment approach to traumatic hand injuries we divided into two groups: isolated trauma of and combined trauma of a hand. When a diagnosis was formulated, this heading was designated by the letter "P" (polytrauma) with division into subgroups: "+" and "--".

According to the AFC in order to detail the diagnosis and choose the appropriate treatment tactics, we give an example of clinical observation and the formulation of diagnosis.

Clinical case №1. Patient S. was transported by an ambulance team to the emergency department of the 8th Lviv City Hospital from the scene of an accident. Initial diagnosis: "Polytrauma. Blunt chest injury. Pulmonary contussion and laceration on the right lungs. Right-sided hemopneumothorax. Closed ribs fracture at the $4 \mathrm{rd}, 5^{\text {th }}$, 6 th and $7^{\text {th }}$ rib on the right with displacement of fragments. Closed non-displaced intertrochanteric right hip fracture. Open fracture of the 4-5th metatarsal bones of the left hand with displacement of fragments. Lacerated-scalped wound of the left hand with soft tissues defect "

The above diagnosis provides information on multiple injuries, localization of the wound of the hand and the absence of soft tissues, but without information to select the best tactics for surgical treatment and archiving data for further correct analysis of the results of treatment.

The diagnosis given by our classification will be as follows. "Lacerated-scalped wound of the left hand with soft tissue defect". L(F5med,s+Dmed,s+min,d),Ili,VTpt,P+» (Fig.1). Thanks to clear detail, we receive information to choose the method of plastic STD. Thus, F5med,s+Dmed,s+min, d, namely the article " $\mathrm{d}$ " indicates the presence of damage to the hand with a deep soft tissues defect and necessity of using plastic full-layered vascularized tissues. And the article "min" focuses on the choice of close STD by using local tissues, as the area of STD $\leq 25 \%$. And F5med,s+Dmed,s gives us information that these wound defects, because they are superficial, can be closed by free thin skin graft. The article " $\mathrm{P}+$ " indicates that the hand trauma is one of the constituent of the polytrauma and the patient's condition does not allow the plastic closure of the wound defect in the urgent order. In this case, the surgery is divided into stages by technology "damage control". In the first stage, primary surgical debridement of the wound and stabilization of the fractures of the metacarpal bones were performed in urgent order. Plastic closure of STD in this case is performed stage III, after stabilization of the patient's condition and the wound preparation for closure. In this case, the soft tissue defect of the back of the hand was closed with local tissue and a free thin skin graft with a thickness of $0.3 \mathrm{~mm}$. STD on the dorsal surface at the 5th finger is also closed with a free thin skin graft. Good functional ( 9 points) and cosmetic (7 points) results were obtained (Fig. 2), and 6 months after the injury -9 and 8 .

Clinical case №2. Patient P.. Diagnosis: Thermo-mechanical wound of the left hand with a soft tissue defect. L(f1, min, $\mathrm{s}+\mathrm{f} 2, \mathrm{~min}, \mathrm{~d}+\mathrm{f} 3, \mathrm{~min}, \mathrm{~s}+\mathrm{d}, \mathrm{min}, \mathrm{p}$ ), Ili,VTmt,P-. (Fig. 3).

Clinical case №3. Patient R.. Diagnosis: Posttraumatic wound of the left hand with a soft tissue defect. L(Tmed,s+MPmed,s+Hmax,d+Dmed,s+d), Ili,VTpt,P-. C.D. Using McGregor flap to plastic soft tissue defect. (Fig. 4).

\section{CONCLUSIONS}

The proposed systematization of post-traumatic soft tissue defects of the hand allows to choose the best method of surgical treatment and get good results. The abbreviation of the names of the classification series allows to create an electronic archive of the database for further sampling and analysis.

\section{REFERENCES}

1. Miranda B.H., Spilsbury Z.P., Rosala-Hallas A. Hand trauma: A prospective observational study reporting diagnostic concordance in emergency hand trauma which supports centralised service improvements. J Plast. Reconstr. Aesthet. Surg. 2016; 69:1397-1402.

2. Ootes D., Lambers K.T., Ring D.C. The epidemiology of upper extremity injuries presenting to the emergency department in the United States. Hand. 2012;7:18-22.

3. Omar M.T., Hassan A.A. Evaluation of hand function after early excision and skin grafting of burns versus delayed skin grafting: a randomized clinical trial. Burns. 2011;37 (4): 707-713.

4. Sarygin P.B., Moroz V.Y., Vahanova N.A. et al. Hyrurhicheskoe lechenue posleogodovuch defectov kisty. Annalu hiryrgii. 2015;3:37-42. (in Russian).

5. Fistal E.Ya., Rospopa Ya.A., Guryanov V.G. Opredelenie metricheskoy haracteristiki obshirnyih mehanicheskih ran konechnostey vavisimosti ot lokalizatsii porazheniya. Ukrainkiy zhurnal hirurgii 2013; (2): 41-46. (in Russian).

6. Slesarenko S.V., Badyil P.A., Slesarenko K.S. Algorytm plastychnoi reconstrykcii pru ranevuch defectach. Plastychna, rekonstryktyvna ta estetychna hiryrgia. 2015;(1): 6-22.

7. Kurinnyi I.M. Kilkisna ocinka stupenia anatomychnuh vtrat pru polistrukturnuh yhkodgen verhnoi kincivky ta ii zastosyvannia pru analizi viddalenuh rezyltativ likyvannia. Trauma. 2012;1:17-32. (in Ukrainian).

8. Budnevskiy A.V., Cveticov L.N., Andreeva A.A. Oput prumenenia mobylnogo prulogenia "wounddesk" dlia ocenky dynamicu reparacii experementalnuch ran. Modelyivannia, optymizacia i informatuvnuch technologii. 2017; (1): 27-31. (in Russian).

\section{ORCID and contributionship:}

Ihor R. Trutyak: 0000-0001-8157-3449 A,E,F

Nazar R. Kalynovych: 0000-0003-2202-6810 A,D

Roman I. Trutiak: 0000-0002-6156-1587 C,D

Maria Y. Kuzeikiv: 0000-0002-3960-2880 B,D

\section{Conflict of interest:}

The Authors declare no conflict of interest. 


\section{CORRESPONDING AUTHOR}

Nazar R. Kalynovych

Danylo Halytsky Lviv National Medical University

69 Pekarska st., 79010 Lviv, Ukraine

tel: +380936246754

e-mail: nazarkalynovych@yahoo.com

Received: 27.05 .2020

Accepted: 01.06 .2021

A - Work concept and design, B - Data collection and analysis, C - Responsibility for statistical analysis,

D-Writing the article, $\mathbf{E}$-Critical review, $\mathbf{F}$ - Final approval of the article 